Woch M. 2012. Antropofity znalezione w trakcie badań archeobotanicznych średniowiecznego Krakowa - W: A. Mueller-Bieniek (red.), Rośliny w życiu codziennym mieszkańców średniowiecznego Krakowa, s. 185-209. Instytut Botaniki im. W. Szafera PAN, Kraków.

ZAJAC M. \& ZAJAC A. 2014. Survival problems of archaeophytes in the Polish flora. - Biodiversity: Research and Conservation 35(1): 47-56.

ZAJAAC M., ZAJAC A. \& TOKARSKA-GUZIK B. 2009. Extinct and endangered archaeophytes and the dynamics of their diversity in Poland. - Biodiversity: Research and Conservation 3: 17-24.

ZARZYCKI K. \& SzeląG Z. 2006. Red list of the vascular plants in Poland. - W: Z. MireK, K. ZarZycki,

W. Wojewoda \& Z. SzeląG (red.), Red list of plants and fungi in Poland, s. 11-20. W. Szafer Institute of Botany, Polish Academy of Sciences, Kraków.

AdAm KaPler, Zakład Botaniki Konserwatorskiej, Polska Akademia Nauk Ogród Botaniczny - Centrum Zachowania Różnorodności Biologicznej w Powsinie, ul. Prawdziwka 2, 02-973 Warszawa,Polska; e-mail: a.kapler@obpan.pl

Wptynęto: 04.08.2020 r.; przyjęto do druku: 29.12.2020 r.

DOI: https://doi.org/10.35535/ffgp-2020-0059

\title{
Sparganium angustifolium i S. minimum (Sparganiaceae) w Tatrach - problemy $z$ identyfikacją gatunków
}

Dotychczas okazy Sparganium L., oznaczane jako S. angustifolium F. Michx., znaleziono w Tatrach na kilku stanowiskach, zarówno na Słowacji, jak i w Polsce. We wszystkich przypadkach były to osobniki płonne.

Celem pracy była analiza wszystkich dostępnych danych dotyczących stanowisk Sparganium angustifolium w Tatrach. W tym celu prześledzono literaturę dotyczącą tematu (od pierwszego doniesienia o wystąpieniu tego gatunku na terenie Tatr) oraz dokładnie obejrzano wszystkie okazy zielnikowe w zielnikach: Instytutu Botaniki UJ (KRA), Instytutu Botaniki im. W. Szafera PAN (KRAM) oraz w zielniku Z. Radwańskiej-Paryskiej przechowywanym w Ośrodku Dokumentacji Tatrzańskiej Tatrzańskiego Parku Narodowego. Okazy zielnikowe pochodzące z tatrzańskich stanowisk porównano z materiałem obserwowanym in situ (w Toporowym Stawie Wyżnym) oraz innymi okazami zielnikowymi S. angustifolium i S. minimum zgromadzonymi w krakowskich zielnikach (KRA i KRAM).

Sparganium angustifolium (jeżogłówka pokrewna), gatunek na terenie Polski zagrożony wyginięciem (EN - KAźMIERCZAKOWA i in. 2016), jest rzadkim reliktem glacjalnym o zasięgu cyrkumborealnym (HultÉn \& FRIES 1986). W Europie jego zasięg obejmuje Półwysep Skandynawski, Wielką Brytanię i Islandię, bardziej na południe występuje na oderwanych stanowiskach, znajdujących się głównie w górach, m.in. w Alpach i Karpatach. Na terenie Polski rośnie w jeziorach Pomorza Zachodniego (SzMEJA 2014) oraz na izolowanym stanowisku w Tatrach, gdzie po raz pierwszy odnalazł go Krupa, po słowackiej stronie Tatr w Pośrednim Rohackim Stawie. Znalezisko to potwierdził Kotula, jednak ze względu na obecność jedynie okazów płonnych nie był pewny poprawności oznaczenia 
(KotUla 1889-1890). Dokładniejsze informacje na temat występowania S. angustifolium w Pośrednich Rohackich Stawach (Pośrednim i Małym) podał Dostál (1929). Kolejne stanowisko jeżogłówki w stanie płonnym, oznaczonej również jako $S$. angustifolium, zostało odnalezione przez Radwańską-Paryską w 1951 r. po polskiej stronie Tatr w Toporowym Stawie Niżnym (RADWAŃSKA-PARYSKA 1981). Po 1976 r. jeżogłówki tam nie odnaleziono (MireK \& PięKoŚ-Mirkowa 2008a), natomiast odkryto ją w znajdującym się powyżej Toporowym Stawie Wyżnim (PiĘKoś-Mirkowa 1982). Była tam obserwowana od lat 70. XX w., przy czym przez kilka lat (koniec lat 90. XX w.) nie odnajdowano jej tam (MireK \& PięKoś-Mirkowa 2008a). Jeżogłówka prawdopodobnie rośnie w Toporowym Stawie Wyżnim od bardzo dawna, o czym świadczy okaz zielnikowy zebrany przez nieznanego badacza w 1926 r. (KRAM). Płonne osobniki jeżogłówki obserwowane były także w 2010 r. w niewielkim zagłębieniu wypełnionym wodą znajdującym się przy czerwonym szlaku z Toporowej Cyrhli na Psią Trawkę, powyżej Toporowych Stawów (A. Koczur, mat. niepubl.). W 2019 r., pomimo intensywnych poszukiwań, stanowiska tego nie udało się potwierdzić. Kolejne stanowisko jeżogłówki, oznaczonej jako S. angustifolium (również w stanie płonnym) zostało odnalezione w 2003 r. w Niżnym Żabim Stawie Białczańskim (DíTĚ $\mathrm{i}$ in. 2004).

Nad Toporowym Stawem Wyżnim, w południowo-wschodniej części torfowiska, przy południowo-wschodniej krawędzi lustra wody, czyli tam skąd wcześniej podawano Sparganium angustifolium (jako S. affine) (PIĘKOŚ-Mirkowa 1982), 18.08.2019 r. zaobserwowano owocujące osobniki jeżogłówki (Ryc. 1), zarówno formy wodne, jak i lądowe. Na powierzchni $25-30 \mathrm{~m}^{2}$ rosło około 40 owocujących osobników (Ryc. 2). Znajdowały się one w wypłycającym się zbiorniku i na jego obrzeżach. Okazało się, że jest to S. minimum Wall. (jeżogłówka najmniejsza). Osobniki owocujące obserwowane były również trzy lata wcześniej, 20.08.2016 r. (P. Kauzal, mat. niepubl.), jednak wtedy nie zweryfikowano ich przynależności gatunkowej. Naliczono wtedy około 30 pędów generatywnych rosnących na powierzchni ok. $20 \mathrm{~m}^{2}$.

Sparganium minimum jest gatunkiem znacznie częściej spotykanym niż S. angustifolium, a zasięgi obu gatunków częściowo się pokrywają (HulTén \& Fries 1986). Jest to również gatunek o zasięgu cyrkumborealnym, który obejmuje część Wysp Brytyjskich i Półwyspu Skandynawskiego, a także Niż Środkowo- i Wschodnioeuropejski. W Polsce występuje na rozproszonych stanowiskach na niżu, a także w pasie wyżyn i w Sudetach (ZAJẠC \& ZAJĄC 2001). Z Karpat Zachodnich podaje go DostÁL (1989) ze słowackiej części Borów Orawskich. Z polskich Karpat jeżogłówka najmniejsza dotychczas znana była tylko z Kotliny Orawsko-Nowotarskiej (KoczUR 2006). Występuje tam na torfowisku Puścizna Rękowiańska w kilku dołach potorfowych i wypływających z torfowiska potokach (Koczur 2008). Obserwowano tam wyłącznie formy wodne, zarówno kwitnące i owocujące, jak i płonne. Z Tatr dotychczas nie była podawana. W Czerwonej księdze Karpat Polskich (MireK \& PięKOŚ-Mirkowa 2008b) gatunek ten ma status zagrożonego wymarciem (EN), a na Polskiej czerwonej liście paprotników i roślin kwiatowych (KAŹMIERCZAKOWA i in. 2016) umieszczony został jako bliski zagrożenia (NT).

Obecność w Tatrach wyłącznie płonnych osobników była przyczyną trudności w oznaczeniu gatunków jeżogłówki. KotULA (1889-1890), publikujący po raz pierwszy informację 
o obecności Sparganium angustifolium w Tatrach, nie był pewny oznaczenia, gdyż zamieścił przy tym gatunku znak zapytania. Dostál (1929) jednoznacznie potwierdził obecność S. angustifolium w Rohackich Stawach. RADWAŃSKA-PARYSKA (1981), oznaczając okazy zebrane w Toporowym Stawie Niżnym porównywała je z okazami ze Stawów Rohackich. Zwróciła uwagę na ich podobieństwo: płonne osobniki o liściach charakterystycznie wypukłych po jednej stronie, bez nerwu środkowego. Prawdopodobnie S. minimum nie brano pod uwagę, gdyż w przeciwieństwie do S. angustifolium nie były znane żadne jego stanowiska z Tatr i Podtatrza.

Analiza okazów zielnikowych potwierdza występowanie Sparganium angustifolium w obu Pośrednich Rohackich Stawach. Okazy zebrane przez Kotulę w 1885 r., Radwańską-Paryską w 1947 r. (KRAM), Švestkę w 1930 r. (KRA) oraz Radwańską-Paryską w 1946 r. (zielnik Z. Radwańskiej-Paryskiej przechowywany w Ośrodku Dokumentacji Tatrzańskiej Tatrzańskiego Parku Narodowego) mają bardzo wąskie, ostro zakończone liście (RoTHMALER 1995) ze słabo widocznym nerwem głównym u części z nich oraz układem komórek, jak u innych okazów S. angustifolium zgromadzonych w zielnikach. Okazy z Toporowego Stawu Wyżniego, zebrane w 1926 r. (KRAM), mają liście nieco szersze, cienkie, tępo zakończone, bez nerwu głównego (RoTHMALER 1995) i z charakterystycznym układem komórek, jak u innych okazów zielnikowych S. minimum. Okazy z Toporowego Stawu Niżniego z 1951 r. oraz Małego Stawu Rohackiego z 1946 r. zebrane przez RadwańskąParyską (zielnik Z. Radwańskiej-Paryskiej) różnią się zarówno od tych zaliczonych

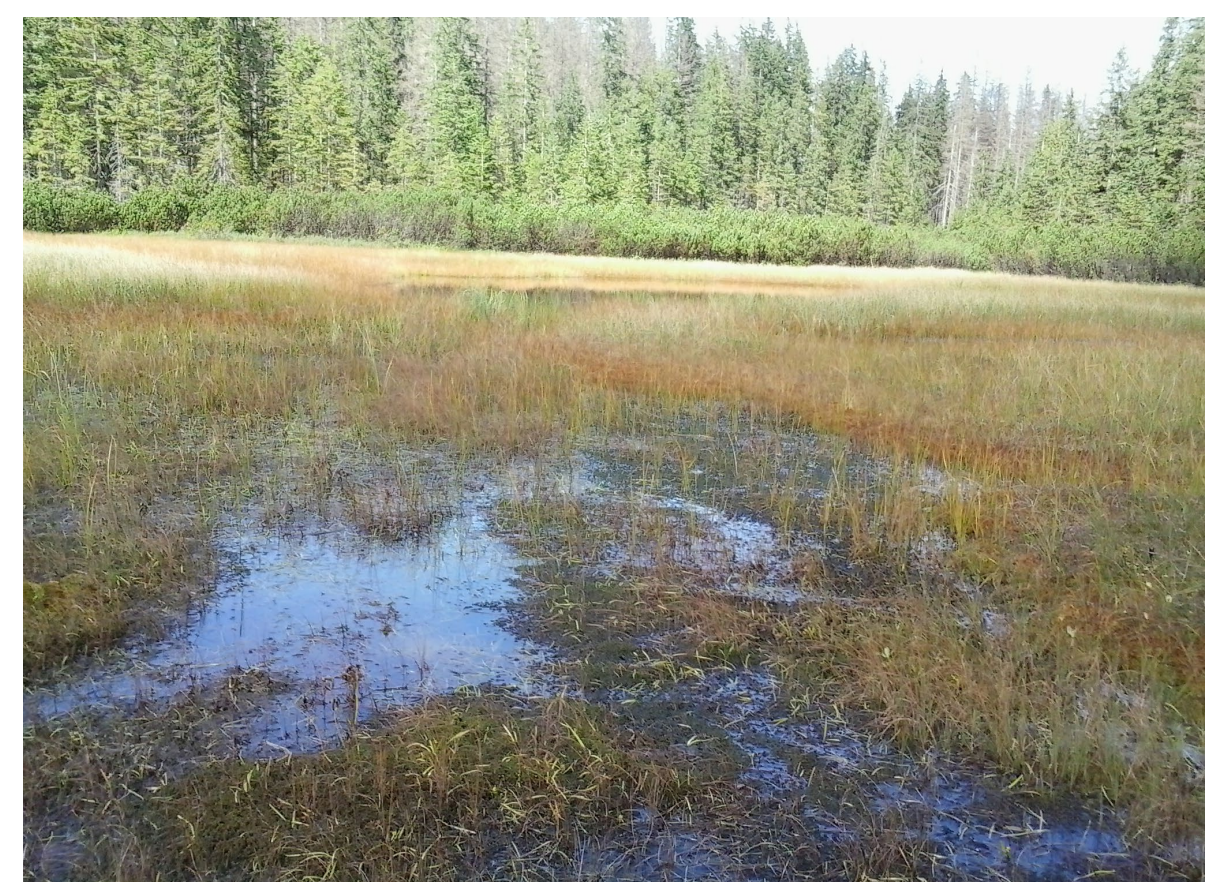

Ryc. 1. Stanowisko Sparganium minimum w Toporowym Stawie Wyżnim (13.09.2019 r., fot. A. Koczur)

Fig. 1. Locality of Sparganium minimum in Toporowy Staw Wyżni lake (13.09.2019, photo by A. Koczur) 


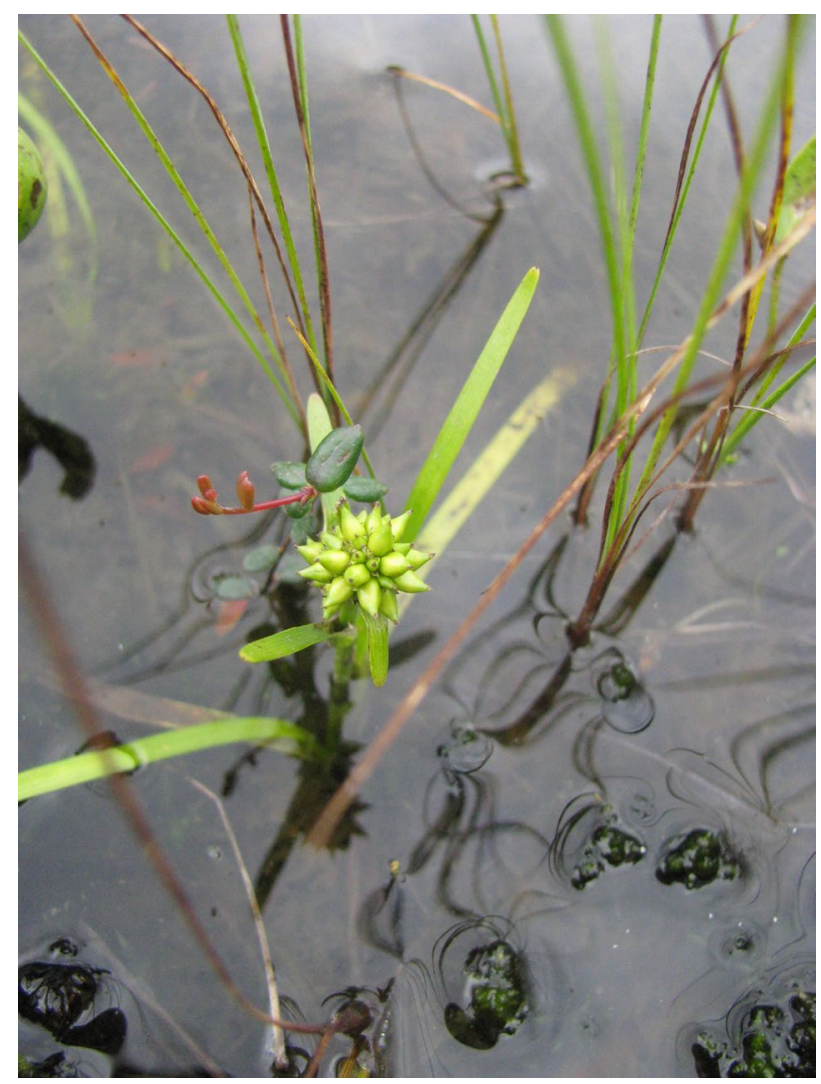

Ryc. 2. Sparganium minimum w Toporowym Stawie Wyżnim (18.08.2019 r., fot. A. M. Ociepa)

Fig. 2. Sparganium minimum in Toporowy Staw Wyżni lake (18.08.2019 r., photo by A. M. Ociepa)

do $S$. angustifolium, jak i do S. minimum. Tępo zakończone liście posiadają słabo widoczny nerw główny, ich szerokość odpowiada okazom $S$. minimum, jednak układ komórek bliższy jest $S$. angustifolium. W tych przypadkach trudno określić przynależność gatunkową.

Oprócz opisywanych gatunków należy tu jeszcze brać pod uwagę wodne formy Sparganium emersum Rehmann tym bardziej, że w zielniku Radwańskiej-Paryskiej znajduje się typowy, owocujący okaz tego gatunku zebrany w Toporowym Stawie Niżnym w 1950 r. Weryfikacja przynależności gatunkowej wymienionych wyżej okazów jest trudna ze względu na brak osobników generatywnych i być może nietypowy pokrój, związany ze specyfiką siedlisk położonych stosunkowo wysoko w górach. Ostateczne potwierdzenie ich przynależności gatunkowej wymagałoby przeprowadzenia badań genetycznych.

Podziękowania. Dziękujemy mgr. inż. Pawłowi Kauzalowi z Tatrzańskiego Parku Narodowego za przekazanie informacji na temat jeżogłówki owocującej w 2016 r. Kustoszom i Pracownikom Zielników Instytutu Botaniki UJ (KRA) i Instytutu Botaniki im. W. Szafera PAN (KRAM) oraz Fundacji im. Zofii i Witolda Paryskich dziękujemy za udostępnienie zbiorów. Mgr. inż. Antoniemu Ziębie z Tatrzańskiego Parku Narodowego dziękujemy za cenne informacje dotyczące badanego gatunku a dr. Danielowi 
Dítě za pomoc w dotarciu do części literatury. Badania sfinansowano częściowo ze środków Funduszu Leśnego Państwowego Gospodarstwa Leśnego Lasy Państwowe przekazanych Tatrzańskiemu Parkowi Narodowemu w 2019 r.

Summary. Sparganium angustifolium and S. minimum (Sparganiaceae) in the Tatra Mountains - problems in species identification. Locations of sterile specimens of bur reed (recognized as Sparganium angustifolium) were found in the Slovakian part of the Tatra Mountains in Pośredni and Mały Rohacki Staw lakes and in Niżny Żabi Staw Białczański lake. In the Polish part of the Tatra Mountains they were found in Toporowy Staw Niżni lake (where since 1976 they have not been found) and Toporowy Staw Wyżni lake. In Toporowy Staw Wyżni lake, fruit-bearing specimens of bur reed were observed on 18 August 2019 (Fig. 1). There were aquatic and land forms and were recognized as S. minimum (Fig. 2). The presence in the Tatra Mountains of exclusively sterile specimens (recognized as S. angustifolium) has caused difficulties with species identification. Analysis of herbarium specimens confirms the appearance of $S$. angustifolium in Rohacki Staw lakes and S. minimum in Toporowy Staw Wyżni lake. All specimens from Toporowy Staw Niżni lake and some of them from Mały Staw Rohacki lake differ from specimens included in species $S$. angustifolium or S. minimum. In those cases it is difficult to determine the species. Besides the abovementioned species, the aquatic forms of $S$. emersum should be taken into consideration. Final confirmation of species affiliation would require genetic tests.

\section{LITERATURA}

DítĚ D., PuKajová D. \& Slivinský J. 2004. Sparganium angustifolium (Sparganiaceae) - a new locality in the Carpathians. - Biologia 59(4): 491-492.

DostáL J. 1989. Nová květena ČSSR. 2. s. 1548. Academia Praha.

DostáL L. 1929. Sparganium affine v Liptovských holích. - Věda a Přŕroda, Praha 10: 315-316.

Hultén E. \& Fries M.1986. Atlas of North European Vascular Plants, North of the Tropic of Cancer. 1-3. Koeltz Scientific Books, Königstein.

Kaźmierczakowa R., Bloch-OrŁowska J., Celka Z., Cwener A., Dajdok Z., Michalska-Hejduk D., Pawlikowski P., SzCZĘ́ŚniaK E. \& ZiARneK K. 2016. Polska czerwona lista paprotników i roślin kwiatowych. s. 44. Instytut Ochrony Przyrody Polskiej Akademii Nauk, Kraków.

KoczUR A. 2006. Importance of vegetation in the Orawsko-Nowotarskie peat bogs to biological diversity in the Polish Carpathians. - Acta Agrophysica 7(2): 383-393.

Koczur A. 2008. Jeżogłówka najmniejsza. Sparganium minimum Wall. - W: Z. MireK \& H. PIĘKoś-MiRKowa (red.), Czerwona Księga Karpat Polskich. Rośliny naczyniowe, s. 554-555. Instytut Botaniki im. W. Szafera PAN, Kraków.

KотUlA B. 1889-1890. Rozmieszczenie roślin naczyniowych w Tatrach. s. 512. Nakł. Wydziału Matematyczno-Przyrodniczego Akademii Umiejętności, Kraków.

Mirek Z. \& Pię́oś-Mirkowa H. 2008a. Jeżogłówka pokrewna. Sparganium angustifolium F. Michx. - W: Z. Mirek \& H. PięKoś-Mirkowa (red.), Czerwona Księga Karpat Polskich. Rośliny naczyniowe, s. 552-553. Instytut Botaniki im. W. Szafera PAN, Kraków.

Mirek Z. \& PięKoś-Mirkowa H. 2008b. Czerwona Księga Karpat Polskich. Rośliny naczyniowe. s. 615. Instytut Botaniki im. W. Szafera PAN, Kraków.

PięKOŚ-Mirkowa H. 1982. Rzadkie taksony roślin naczyniowych na terenie Tatrzańskiego Parku Narodowego - ich zagrożenia ze strony turystyki oraz problemy ochrony. - Studia Naturae, Seria A 22: 79-132.

RADWAŃSKA-PARYSKa Z. 1981. Tatrzańskie notatki florystyczne z Tatr i Podtatrza. - Fragmenta Floristica et Geobotanica 27(3): 349-357. 
RothmaLer W. 1995. Exkursionsflora von Deutschland. Band 3. Gefäßpflanzen: Atlasband. s. 441. Auflage 9. G. Fischer, Jena - Stuttgart.

SzMEJa J. 2014. Sparganium angustifolium Michx. Jeżogłówka pokrewna. - W: R. KaźmierczaKowa, K. ZARZYCKi \& Z. Mirek (red.), Polska Czerwona księga roślin. Paprotniki i rośliny kwiatowe. Wyd. III. s. 661-662. Instytut Ochrony Przyrody, Polska Akademia Nauk, Kraków.

ZAJĄC A. \& ZAJĄC M. 2001. Atlas rozmieszczenia roślin naczyniowych w Polsce. s. xii + 716. Pracownia Chorologii Komputerowej Instytutu Botaniki Uniwersytetu Jagiellońskiego, Kraków.

AnNa Koczur, ul. Kmietowicza 1/4, 30-092 Kraków, Polska; e-mail: koczur.anna@yahoo.com AnNa Maria OcIEPA, FUP Kościelisko, skrytka nr 17, 34-511 Kościelisko, Polska; e-mail: amociepa@interia.pl

Wptynęto: 23.03.2020 r.; przyjęto do druku: 09.11.2020 r.

DOI: https://doi.org/10.35535/ffgp-2020-0060

\section{Nowe stanowiska Orchis pallens (Orchidaceae) na Wyżynie Śląskiej}

Rodzaj storczyk (Orchis L.), liczy 21 gatunków, występujących w Europie, Azji i Afryce północno-zachodniej. W Polsce stwierdzono cztery z nich (CHASE i in. 2015; WCSP 2020).

Orchis pallens L., storczyk blady, to bylina o wysokości 20-35 cm, z 4-6 podługowatojajowatymi liśćmi u nasady łodygi. Ma bladożółte kwiaty, tworzące w kwietniu lub maju jajowate kwiatostany (ZAJĄC \& FIEDOR 2014). Kwiaty storczyka bladego, podobnie jak w przypadku innych przedstawicieli rodzaju, należą do tzw. kwiatów zwodniczych - wabią owady zapylające, lecz nie ofiarują im pokarmu (CLAESSENS \& KLEYNEN 2011). Ponadto VöTH (1982) wskazał zależność pomiędzy budową ostrogi kwiatu O. pallens, a budową kwiatu groszku wiosennego (Lathyrus vernus), opartą na zasadach tzw. mimikry batesowskiej. Podobieństwo to zwiększa szansę wizyty zapylacza (głównie trzmielowate) na zwodniczym kwiecie storczyka w okresie przekwitania nektarodajnych kwiatów groszku. Zasięg gatunku obejmuje południową oraz środkową część Europy od Pirenejów po Kaukaz (BERNACKI i in. 2008; ZAJAc \& FIEDOR 2014). Storczyk blady jest gatunkiem górskim reglowym (ZAJAC 1996), w Polsce narażonym na wyginięcie. Główne zagrożenia dla tego gatunku, to zarastanie i zalesianie muraw oraz w mniejszym stopniu bezpośrednie niszczenie stanowisk np. przez motory krosowe (ZAJAC \& FIEDOR 2014; KAźMIERCZAKowA $\mathrm{i}$ in. 2016). Występuje w grądach (Tilio-Carpinetum), zaroślach (Prunetalia) i murawach kserotermicznych.

W Polsce Orchis pallens został odnotowany na ponad 30 stanowiskach, zlokalizowanych głównie na Pogórzu Cieszyńskim oraz w Karpatach Zachodnich (Dolina Dunajca) - obecnie występuje na 23 z nich (ZAJAc \& FIEDOR 2014). Jak dotąd, najdalej wysunięte na północ stanowiska tego gatunku w Polsce były położone na Wyżynie Miechowskiej (MATYJASZKIEWICZ 1990; BiNKIEWICZ 2010). 